\title{
Effect of carbon source availability and growth phase on expression of Corynebacterium glutamicum genes involved in the tricarboxylic acid cycle and glyoxylate bypass
}

Correspondence

Hideaki Yukawa

mmg-lab@rite.or.jp

Sung Ok Han

samhan@korea.ac.kr

Received 21 April 2008

Revised 23 June 2008

Accepted 27 June 2008

\section{Sung Ok Han, ${ }^{1,2}$ Masayuki Inui ${ }^{1}$ and Hideaki Yukawa ${ }^{1}$}

\author{
${ }^{1}$ Molecular Microbiology and Biotechnology Group, Research Institute of Innovative Technology for \\ the Earth (RITE), Kyoto 619-0292, Japan \\ ${ }^{2}$ College of Life Sciences and Biotechnology, Korea University, Seoul 136-701, Republic of Korea
}

\begin{abstract}
The effect of different carbon sources on the expression of tricarboxylic acid (TCA) cycle genes, along with glyoxylate bypass genes, in Corynebacterium glutamicum was determined. All TCA cycle genes were coordinately expressed in medium containing acetate. Growth in the presence of acetate gave rise to abundant expression of most TCA cycle genes, with the level of $g / t A$ transcript being the highest. However, when the cells entered the stationary phase triggered by acetate exhaustion, all genes were repressed, except sucCD and $m d h B$, which were slightly induced. Acetate withdrawal from the growth medium during the exponential phase also led to rapid repression of most TCA cycle genes and a corresponding twofold increase in the expression of sucCD, which were strongly induced by citrate and succinate. In addition, glucose depletion during the stationary phase led to a corresponding 8-20-fold induction of the sucCD, ace $A$ and $a c e B$ genes. Addition of glucose to acetate medium resulted in about 10 -fold induction of sucCD. The strong dependence of TCA cycle sucCD and glyoxylate bypass ace $A$ and ace $B$ expression on carbon source availability was confirmed and the regulatory system will be studied precisely.
\end{abstract}

\section{INTRODUCTION}

Corynebacterium glutamicum, a non-pathogenic, facultative anaerobic Gram-positive soil bacterium, is widely used in the industrial production of numerous metabolites, including amino acids and organic acids (Kinoshita et al., 1957; Liebl, 2005; Nishimura et al., 2007). In contrast to closely related, medically important pathogenic species, such as Corynebacterium diphtheriae and Mycobacterium tuberculosis, C. glutamicum is generally recognized as a nonhazardous organism (Dover et al., 2004; Funke et al., 1997). Furthermore, this organism has gained increasing interest as a suitable model organism for high-G $+\mathrm{C}$-content Grampositive bacteria in general and for Corynebacterineae, a suborder of the Actinomycetes, in particular.

One of the central metabolic pathways in C. glutamicum and in other aerobic bacteria is the tricarboxylic acid (TCA) cycle, which is responsible for the complete

Abbreviations: CBS, CRP-binding site; CCR, carbon catabolite repression; CRP, CAMP receptor protein; DO, dissolved oxygen; EMSA, electrophoretic mobility shift assay; ORP, oxidation-reduction potentials; qRT-PCR, quantitative real-time reverse transcription PCR; RLM-RACE, RNA ligase-mediated rapid amplification of cDNA ends; TCA cycle, tricarboxylic acid cycle. oxidation of acetyl-CoA derived from various substrates and for the provision of precursors for amino acid biosynthesis. TCA cycle intermediates are commonly used by other metabolic reactions in a wide variety of cell types. Due to the commercial importance of the amino acids and organic acids produced by C. glutamicum, the control of TCA cycle enzyme activities has been the subject of intensive studies, and the phenotypes of mutants affecting TCA cycle genes have been analysed (Eikmanns et al., 1994, 1995; Molenaar et al., 1998, 2000; Usuda et al., 1996; Wittmann \& De Graaf, 2005). However, limited work has been devoted to the regulation of the expression of $C$. glutamicum TCA cycle genes in response to different growth phases and carbon sources. Recently we have reported the transcription of C. glutamicum genes involved in the TCA cycle and glyoxylate bypass (Han et al., 2008). In fact, aspects of the regulation of only three TCA cycle enzymes in C. glutamicum, citrate synthase (encoded by $g l t A$ ), aconitase (encoded by $a c n$ ), and isocitrate dehydrogenase (encoded by $i c d$ ), have been described (Eikmanns et al., 1994, 1995; Krug et al., 2005).

C. glutamicum can use a variety of carbohydrates and organic acids as carbon and energy sources (Kinoshita \& Tanaka, 1972; 
Liebl, 1991). As carbon sources, glucose and acetate have been shown to serve as substrates for amino acid production by $C$. glutamicum. The genes required for the utilization of a specific carbon source are, in most cases, expressed only if that carbon source is present in the medium and if preferred carbon sources, such as acetate and glucose, are absent from the growth medium. These two processes in C. glutamicum are referred to as substrate induction and carbon catabolite repression (CCR), respectively (Letek et al., 2006). CCR is an environment-sensing mechanism used by bacteria to establish priorities in carbon metabolism. Transcriptional regulation is modulated by the level of cAMP and cAMP receptor protein (Crp), a global transcriptional regulator. It has been reported that the activities of Bacillus subtilis TCA cycle enzymes, particularly citrate synthase and aconitase, are severely depressed when glucose is supplied (Cox \& Hanson, 1968; Hanson \& Cox, 1967; Ohne, 1974) and that the dyad symmetry sequence located in the aconitase gene promoter region is the target for CCR (Fouet et al., 1990; Fouet \& Sonenshein, 1990; Jin \& Sonenshein, 1994; Rosenkrantz et al., 1985). Expression of Escherichia coli aconitase genes is also subject to CCR mediated by Crp (Cunningham et al., 1997; Gruer \& Guest, 1994; Gruer et al., 1997). The transcriptional regulator GlxR contains a domain with similarity to the cAMP-binding motifs of Crp from E. coli and, in fact, cAMP is essential for binding of GlxR to the aceA/aceB intergenic region in C. glutamicum (Kim et al., 2004; Letek et al., 2006). The regulation of C. glutamicum metabolism in the presence of various carbon sources clearly differs from that of E. coli or B. subtilis (Gerstmeir et al., 2003; Hayashi et al., 2002; Letek et al., 2006; Muffler et al., 2002). No direct evidence has been found of a CCR system in C. glutamicum (Bruckner \& Titgemeyer, 2002; Gerstmeir et al., 2003; Han et al., 2007), although a CCR-like phenomenon has been reported from cells grown on medium containing glucose with either glutamate (Gerstmeir et al., 2003; Kramer et al., 1990; Kronemeyer et al., 1995) or ethanol (Arndt \& Eikmanns, 2007; Kotrbova-Kozak et al., 2007). However, mechanisms of true induction and repression in the TCA cycle have not been studied in depth.

To add to our previous findings on transcription of TCA cycle genes (Han et al., 2008) and to define the regulatory networks responsive to the TCA cycle, we performed a detailed transcriptional analysis of TCA cycle genes in various growth phases and with various carbon sources to assess their effects on mRNA levels of different sets of genes. We uncovered a unique pattern of gene expression that alternates between elevated and diminished levels of contiguous pairs of TCA cycle genes in response to culture conditions. The data indicate that the TCA cycle is regulated by the availability of carbon sources such as acetate and glucose, and that CCR protein might be involved in this global regulation.

\section{METHODS}

Growth conditions and analytical methods. C. glutamicum $\mathrm{R}$ (Kinoshita et al., 1957; Liebl, 2005; Yukawa et al., 2007) was used as the source of genomic DNA and total RNA. The organism was cultured at $33{ }^{\circ} \mathrm{C}$ with constant agitation (1000 r.p.m.) and aeration (1 volume per volume $\min ^{-1}$ ) in $500 \mathrm{ml}$ mineral salts medium described previously (Han et al., 2007) in a 1-litre jar fermenter (BMJ01PI, Biott). The sole carbon and energy source was provided by glucose, acetate, pyruvate, lactate, citrate, succinate or malate (200 $\mathrm{mM}$ each). Cells were subcultured in medium containing the same carbon source before they were added to fresh medium as inoculants. The $\mathrm{pH}$ was monitored using a $\mathrm{pH}$ controller (DT-1023, Biott) and maintained at 7.6 by supplementing the medium with $5 \mathrm{M}$ $\mathrm{NH}_{3}$ and $1 \mathrm{M} \mathrm{HCl}$. Cell growth was monitored continuously by measuring $\mathrm{OD}_{610}$. Cultured samples were centrifuged $\left(10000 \mathrm{~g}, 4{ }^{\circ} \mathrm{C}\right.$, $3 \mathrm{~min}$ ), and the supernatants were analysed for sugars and organic acids. Organic acids were quantified by high-performance liquid chromatography (8020 chromatograph, Tosoh Corporation) equipped with a UV detector and conductivity meter, and a TSKgel OApak-A column (Tosoh Corporation) operating at $40{ }^{\circ} \mathrm{C}$ with a $0.75 \mathrm{mM} \mathrm{H}_{2} \mathrm{SO}_{4}$ mobile phase at a flow rate of $1.0 \mathrm{ml} \mathrm{min}^{-1}$. The concentrations of glucose were measured by an enzyme electrode glucose sensor (BF-4, Oji Scientific Instruments).

Nucleic acid isolation. Chromosomal DNA was isolated using a Genomic DNA Purification kit (Promega) according to the manufacturer's instructions. Total RNA was extracted from broth cultures using a Qiagen RNeasy kit (Qiagen) as previously described (Han et al., 2007).

Quantitative real-time reverse transcription PCR (qRT-PCR). mRNA was quantified with an ABI Prism 7000 RT-PCR system (Applied Biosystems). A 50 ng total RNA sample was used per RTPCR with each primer pair using a QuantiTect SYBR Green RTPCR kit (Qiagen) according to the manufacturer's instructions. Negative controls with no reverse transcriptase were included with each RNA sample to rule out DNA contamination. DNA templates without reverse transcriptase were included as positive controls. Amplicons were run on a $2 \%(\mathrm{w} / \mathrm{v})$ agarose gel to verify that only a single band was produced. The target gene transcripts were normalized to the reference gene transcript (16S rRNA) from the same RNA sample. Each gene was analysed using RNA isolated from three independent samples. The comparative threshold cycle $\left(C_{\mathrm{t}}\right)$ method (Applied Biosystems) was used to quantify relative expression, with a $C_{\mathrm{t}}$ being defined as the cycle at which the reporter fluorescence is distinguishable from the background in the extension phase of the PCR. The $C_{t}$ values were computed as described previously (Bustin, 2002; Winer et al., 1999). The relative change in transcription rate was determined as $2^{-\left[\Delta \Delta C_{t}\right]}$, with $\Delta \Delta C_{t}$ equal to the difference of the measured crossing points for the test and the control condition.

Purification of GlxR. Primers glxR-TF ( $5^{\prime}$-caccGTGGAAGGTGTACAGGAGAT) and glxR-TR (5'-TCGAGCGCGACGTGCCAAAT) were used to amplify the $g l x R$ gene from $C$. glutamicum. The amplified $g l x R$ gene was cloned into pET100/D-TOPO, which allows translational fusion between a C-terminal 6-His tag and the target gene, and then transformed into E. coli BL21 Star for overexpression (Invitrogen). The enzyme was purified using a nickel-nitrilotriacetic acid column (Invitrogen) and dialysed against $20 \mathrm{mM}$ Tris ( $\mathrm{pH} 7.0$ ) and $1 \mathrm{mM}$ dithiothreitol. Where indicated, the 6-His tag was removed by treatment with EnterokinaseMax (Invitrogen) after purification. Samples taken at different stages of the purification process and the purified protein were analysed by SDS-10 \% PAGE as described by Laemmli (1970). Samples mixed with Tris/glycine SDS sample buffer (Invitrogen) $(1: 1, \mathrm{v} / \mathrm{v})$ were denatured at $100{ }^{\circ} \mathrm{C}$ for 5 min and applied to a $10 \%$ polyacrylamide gel using a mini-Protean II system (Bio-Rad). Gels were stained with colloidal Coomassie Blue stain (Genomic Solutions) to visualize proteins. 
Electrophoretic mobility shift assay (EMSA). To test the binding of GlxR to putative target promoters, purified GlxR protein $(50-$ $500 \mathrm{ng}$ ) was mixed with DNA fragments (mostly $200 \mathrm{bp}$; final concentration, $10-100 \mathrm{ng}$ ) in a total volume of $10 \mu \mathrm{l}$. The binding buffer ( $\mathrm{pH}$ 7.4) contained $150 \mathrm{mM} \mathrm{KCl}, 0.1 \mathrm{mM}$ dithiothreitol, $0.1 \mathrm{mM}$ EDTA, $10 \mathrm{mM}$ Tris and $0.2 \mathrm{mM}$ cAMP. The reaction mixture was incubated at room temperature for $30 \mathrm{~min}$ and then loaded onto a $5 \%$ native polyacrylamide gel. Electrophoresis was performed at room temperature and $200 \mathrm{~V}$ using $0.5 \times$ TBE buffer ( $44.5 \mathrm{mM}$ Tris base, $44.5 \mathrm{mM}$ boric acid and $1 \mathrm{mM}$ EDTA) supplemented with $0.2 \mathrm{mM}$ cAMP. The gels were subsequently stained using the EMSA kit (Invitrogen) as described by the manufacturer and photographed. All PCR products used in EMSA were purified with the PCR purification kit (Qiagen) and eluted in distilled water.

\section{RESULTS}

\section{Effect of growth phase on expression of genes involved in the TCA cycle and glyoxylate bypass}

To verify whether the TCA cycle genes are coordinately regulated, changes in the expression levels of several TCA cycle genes were monitored during cultivation of $C$. glutamicum with either acetate (Fig. 1) or glucose (Fig. 2) as the sole carbon and energy source. RNA was prepared from the cultures at different growth stages (Figs $1 \mathrm{~N}$ and $2 \mathrm{~N}$ ). The RNA was subjected to qRT-PCR analyses using specific primer sets for the TCA cycle genes (Table 1). To ensure that the resulting PCR products were amplified from cDNA, instead of from contaminating chromosomal DNA, reverse transcriptase or total RNA was omitted in control experiments. In these controls, no signal was detected (data not shown).

The pattern of induction by acetate at different growth phases was very similar among all TCA cycle gene transcripts (Fig. 1). Although the errors in expression level were wide, the levels of initial $(0 \mathrm{~h})$ transcription of $g l t A$ and sucCD were considerably higher compared with those of the other TCA genes. In the early stages of growth $(1 \mathrm{~h})$, most TCA cycle gene transcripts were induced in the presence of acetate; the levels of $g l t A$ and aceA mRNA were highest in TCA cycle and glyoxylate bypass, respectively. As the culture entered the mid-exponential growth phase at 2$3 \mathrm{~h}$, the transcription of most TCA cycle genes increased simultaneously and reached maximum levels. After this, the transcription level decreased as the cells adapted to the late exponential phase. Generally, the degree of expression at each growth phase, especially stationary phase, appeared to correlate with the acetate consumption rate (Fig. $1 \mathrm{~N}$ and $\mathrm{O})$. Unlike that of other genes, the expression levels of sucCD and $m d h B$ mRNA were maximal when the cells had completely consumed the acetate in the medium at stationary phase and then gradually decreased as the cells reached the late stationary phase (Fig. $1 \mathrm{~F}$ and $\mathrm{J}$ ). There was a 12 -fold increase in sucCD transcripts associated with
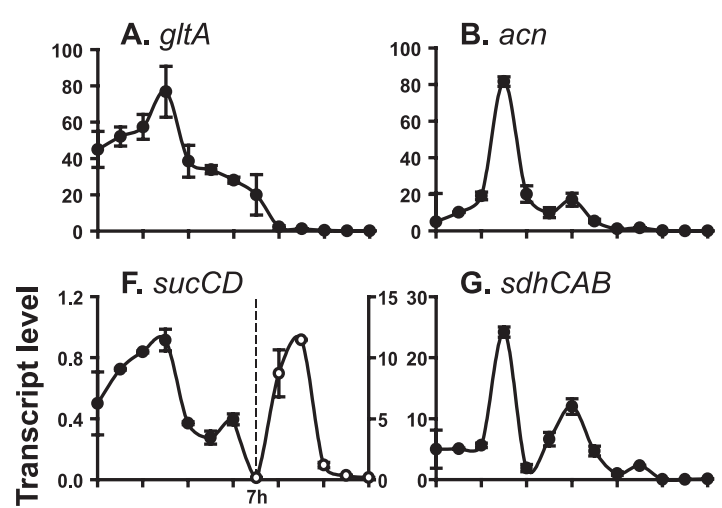

G. $s d h C A B$
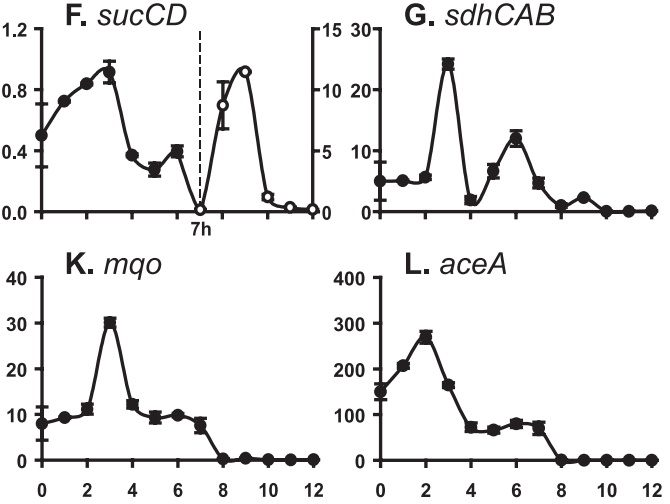

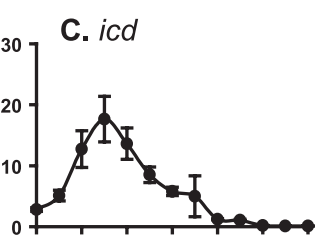

H. fum

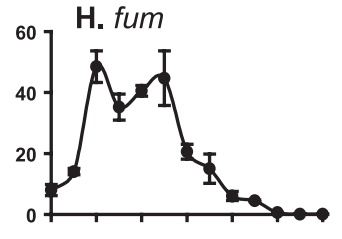

M. $\operatorname{ace} B$

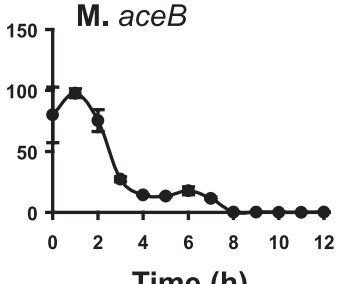

D. odhA

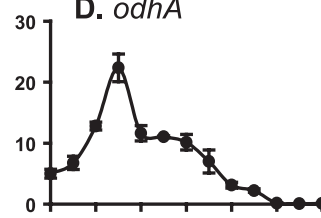

I. $m d h$
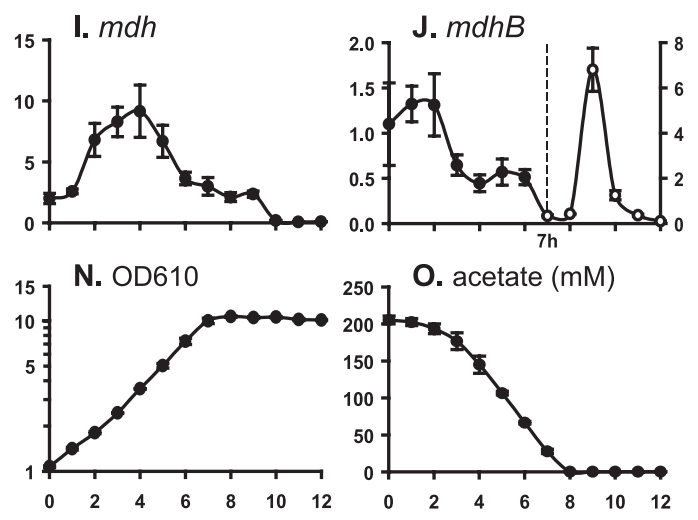

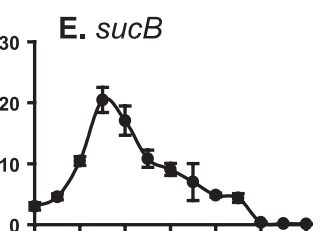

O. acetate $(\mathrm{mM})$

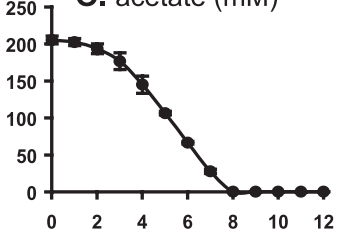

Time (h)

Fig. 1. Relative levels of transcripts of TCA cycle genes at different growth phases in acetate culture. Transcription levels refer to fold changes. Transcriptional expression (A-M) was determined by quantitative RT-PCR with RNA (25 ng) isolated from C. glutamicum cultivated on mineral salts medium containing $200 \mathrm{mM}$ acetate as the sole carbon and energy source. Primers specific for the TCA cycle genes were used to amplify fragments by PCR (see Table 1). (N) C. glutamicum growth curve $\left(\mathrm{OD}_{610}\right)$. (O) Concentration of acetate $(\mathrm{mM})$. The $\mathrm{pH}$ was maintained at 7.6. The error bars represent the standard deviation of three independent experiments. The vertical dashed lines in panels $\mathrm{F}$ and $\mathrm{J}$ indicate an incubation time of $7 \mathrm{~h}$; data to the right of these lines are plotted on the scales to the right. In this and subsequent figures, the data plotted are means $\pm \operatorname{SD}(n=3)$. 

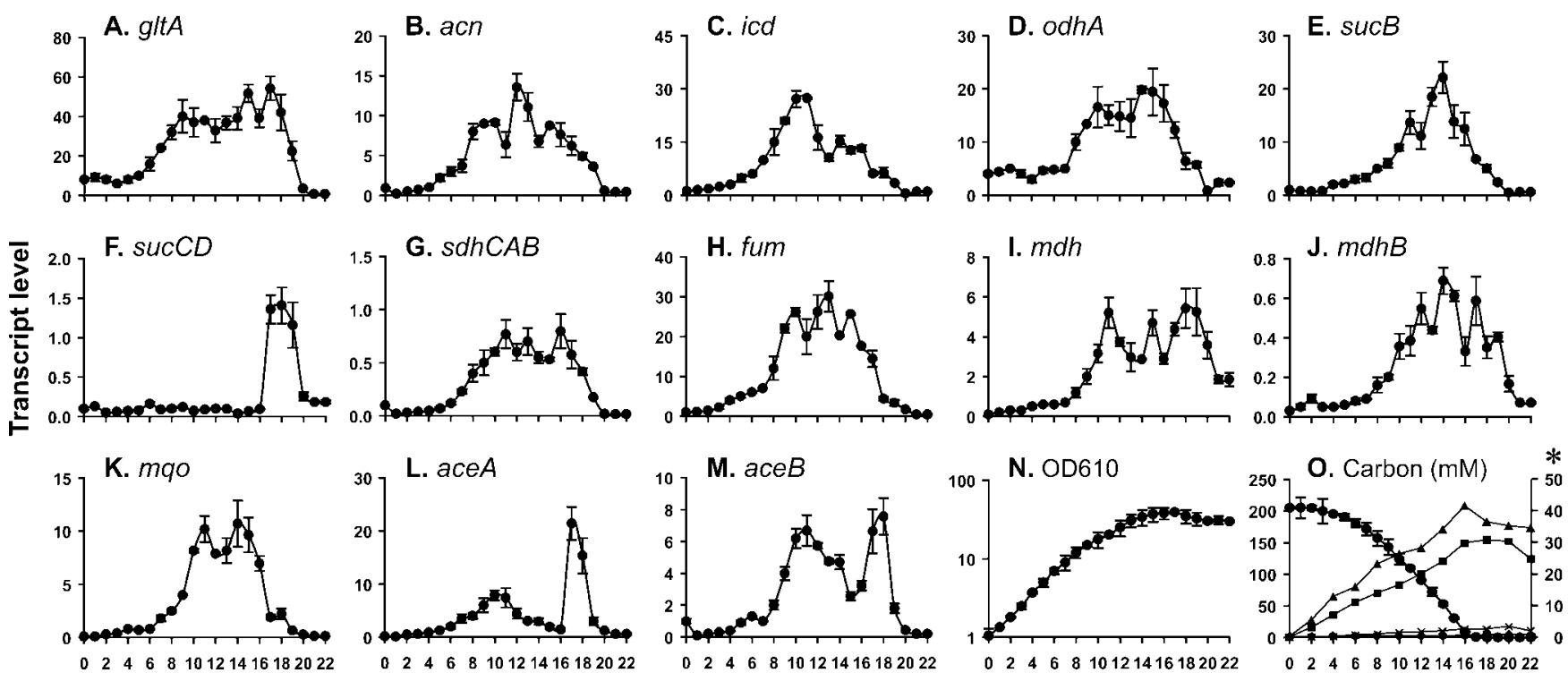

Time (h)

Fig. 2. Relative levels of transcripts of TCA cycle genes at different growth phases in glucose culture. The primers, methods, and other details correspond to those described in Fig. 1. (O) Concentration (mM) of glucose $(\boldsymbol{\bullet})$, acetate* $(\boldsymbol{\square})$, pyruvate* $(\boldsymbol{\Delta})$, lactate $^{\star}(\boldsymbol{\Lambda}, 10 \times)$ and malate ${ }^{*}(\boldsymbol{x})\left(^{*}\right.$ indicates use of $y$-axis scale on right of graph).

simultaneous depletion of acetate in the stationary phase $(9 \mathrm{~h})$ relative to the values observed in the mid-exponential phase $(3 \mathrm{~h})$ (Fig. 1F). In addition, there was a sevenfold increase in $m d h B$ mRNA in the stationary phase $(9 \mathrm{~h})$ compared with the value measured in the exponential phase $(2 \mathrm{~h})$ (Fig. 1J). These observations indicate that most TCA cycle genes of C. glutamicum are constitutively expressed but are induced to express at higher levels in the presence of acetate after a rather short lag period. Reduced expression was observed at later growth stages. The close correlation between the transcription timecourses of TCA cycle genes suggests that these genes are expressed simultaneously to enable acetate utilization.

To determine whether glucose activates TCA cycle gene transcription, RNA was isolated from C. glutamicum at different growth phases in the presence of glucose. The levels of most TCA cycle gene transcripts increased simultaneously from the mid-exponential phase to the early stationary phase, and decreased during the midstationary phase (Fig. 2). The pattern of glucose induction was similar among most TCA cycle genes. However, the mRNA levels of sucCD, $m d h, m d h B$, ace A and aceB increased simultaneously when the cells had completely consumed the glucose in the medium during the stationary phase (Fig. 2). In particular, the highest expression of the sucCD operon, which encodes succinyl-CoA synthetase, was observed when the cells were starved, regardless of whether the cells were grown on acetate or glucose (Figs 1F and $2 \mathrm{~F}$ ). In addition, glucose depletion most strongly induced aceA and $a c e B$ (Fig. $2 \mathrm{~L}$ and M). The levels of aceA and $a c e B$ transcripts in acetate-grown cells were up to
30 -fold higher than those in glucose-grown cells (Figs 1L, and $\mathrm{M}, 2 \mathrm{~L}$ and $2 \mathrm{M}$ ). These data also indicated that either acetate (approx. $30 \mathrm{mM}$ ) or lactate (approx. $400 \mathrm{mM}$ ) accumulated in the medium at $16 \mathrm{~h}$ induced these genes, when the glucose has been completely consumed (Fig. 2O). However, these accumulated carbon sources may not affect the transcripts of genes strongly when glucose remains abundant (Gerstmeir et al., 2003). Interestingly, glucose induced high levels of expression of TCA cycle genes during the early stationary phase, whereas the transcript levels were highest at the mid-exponential phase in acetate medium (Figs 1 and 2).

\section{Effect of carbon depletion on expression of TCA cycle genes}

To determine whether carbon source withdrawal induces or represses TCA cycle gene expression, transcript levels were determined in C. glutamicum before and after starvation of cells grown on acetate (Fig. 3I) or glucose (Fig. 3II) as the sole carbon and energy source. First of all, a carbon-starvation condition was created when exponential-phase cells from medium containing either acetate or glucose were washed with the same medium lacking any carbon source. Expression of most TCA cycle genes, except sucCD, $m d h$ and $m d h B$, which were clearly observed in acetate-fed cells, dramatically decreased when the cells were starved for $2 \mathrm{~h}$ (Fig. 3I). In agreement with the previous section, the genes that were most positively regulated by acetate depletion were sucCD and $m d h B$ (Figs $3 \mathrm{I} \mathrm{F}$ and J). Acetate starvation for about $1.5 \mathrm{~h}$ provoked an 
Table 1. Oligonucleotide primers used in this study

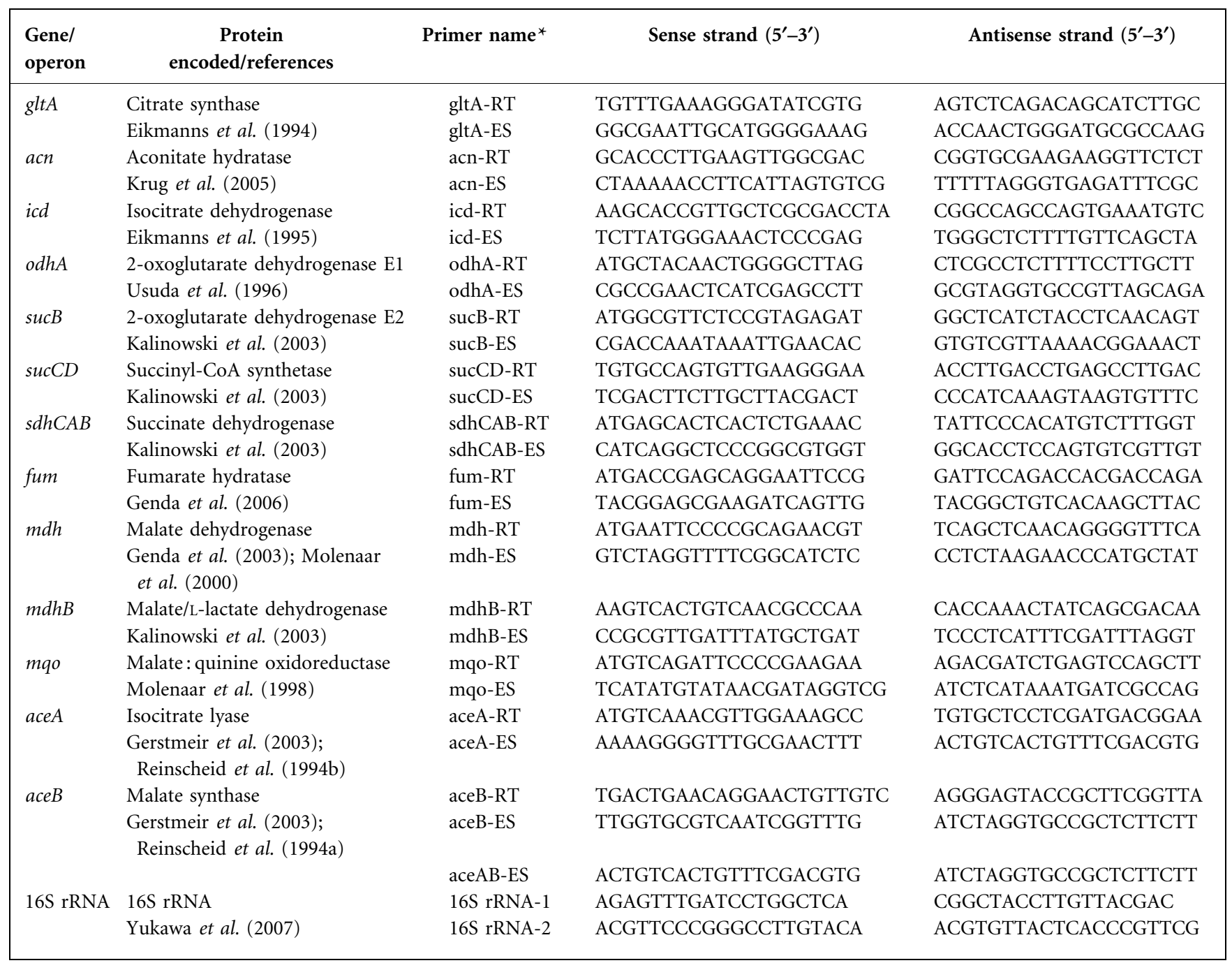

${ }^{\star}$ Primers -RT, used for qRT-PCR; -ES, used for EMSA.

approximately threefold increase in sucCD mRNA (Fig. 3I F). Expression of $m d h B$ was also stimulated by acetate starvation, increasing 1.5-fold after $2 \mathrm{~h}$ (Fig. 3I J). After about $1 \mathrm{~h}$ acetate starvation, transcripts of $m d h$ were depressed, but later markedly increased until about $2 \mathrm{~h}$ of starvation. The levels of $s d h C A B$ transcripts increased during the initial $0.5 \mathrm{~h}$ of starvation, but decreased during the next $1 \mathrm{~h}$ (Fig. 3I G). We next explored whether this induction was specific to acetate withdrawal or was a general consequence of carbon depletion. Accordingly, cells were grown on fermentable glucose and then washed in medium not containing the carbon source. Upon glucose depletion, the expression pattern of TCA cycle genes differed from that upon acetate depletion (Fig. 3). In glucose-starved cells, transcripts of all TCA cycle genes were depressed during the initial $0.5 \mathrm{~h}$ of starvation, but increased during the next $1 \mathrm{~h}$ (Fig. 3II), with the only variation being in the level of expression. Upon further starvation $(2 \mathrm{~h})$, most transcripts decreased (Fig. 3II).
However, up to threefold increases of $m d h, m d h B$ and $m q o$ transcripts were observed after $2 \mathrm{~h}$ starvation (Fig. 3II K).

\section{Effect of glucose supplementation of acetate cultures on expression of TCA cycle genes}

To determine whether glucose acts by repressing transcription of TCA cycle genes involved in the catabolism of acetate, we performed qRT-PCR analysis with specific primer sets. C. glutamicum was grown with acetate (200 mM) until the early exponential phase and then incubated for an additional $2 \mathrm{~h}$ after supplementation with $200 \mathrm{mM}$ glucose. Addition of glucose in the presence of acetate simultaneously induced the expression of 8 out of 13 genes: glt $A$, acn, odhA, sucCD, sdhCAB, mqo, ace $A$ and $a c e B$ (Fig. 4). However, most transcripts, except sucCD, were repressed after the culture had been incubated for $1 \mathrm{~h}$. These transcripts were slightly induced again during the next $1.5 \mathrm{~h}$ incubation, but were almost completely 

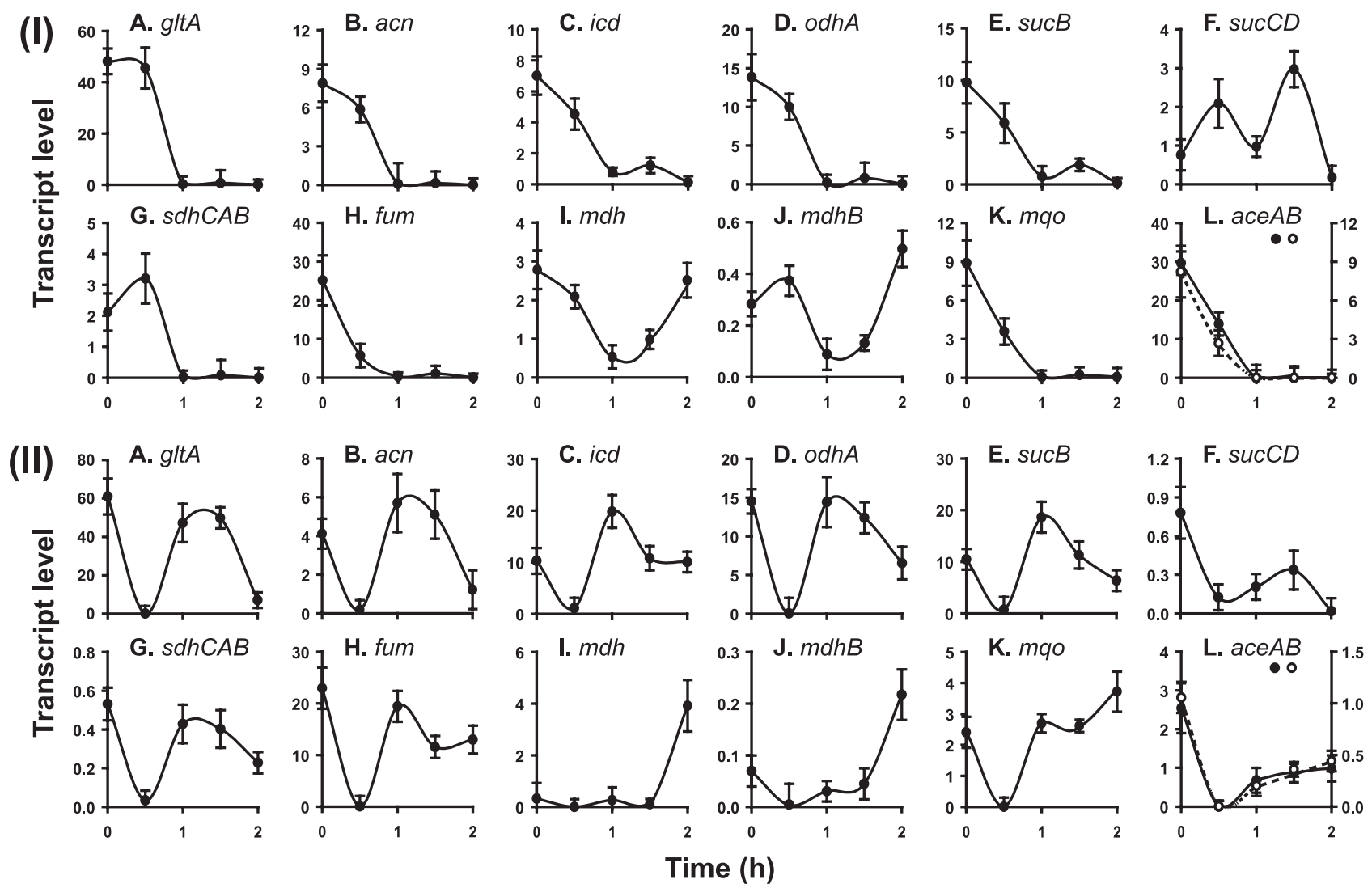

Fig. 3. Level of transcripts of TCA cycle genes analysed by qRT-PCR before and after carbon starvation at exponential phase. Cells grown in mineral salts medium containing $200 \mathrm{mM}$ acetate (I) or glucose (II) as a carbon and energy source were harvested at exponential phase $\left(\mathrm{OD}_{610} 10\right)$ by centrifugation at $6000 \mathrm{~g}$ for $5 \mathrm{~min}$ and washed twice with non-carbon mineral salts medium. Cells were resuspended in non-carbon mineral salts medium to a final $\mathrm{OD}_{610}$ of $1-2$ and incubated for $2 \mathrm{~h}$ at $33{ }^{\circ} \mathrm{C}$. The primers, methods, and other details correspond to those described in Fig. 1. In panel $\mathrm{L}$, the left scale refers to ace $A$ and the right scale to ace $B$.

repressed upon further incubation (2 h) (Fig. 4). The expression of the sucCD operon was most strongly regulated by glucose supplementation (Fig. 4F). Glucose addition provoked about a 10 -fold increase in sucCD transcripts during the $1-1.5 \mathrm{~h}$ incubation, and the expression was then clearly reduced to basal level after $2 \mathrm{~h}$ incubation. In contrast to other genes, the levels of $m d h$ and $m d h B$ transcripts increased during the $2 \mathrm{~h}$ incubation (Figs $4 \mathrm{I}$ and $\mathrm{J}$ ). Glucose addition was associated with decreased icd, sucB and fum expression, after about $0.5-1 \mathrm{~h}$ (Figs $4 \mathrm{C}, \mathrm{E}$ and $\mathrm{H}$ ). After $1.5 \mathrm{~h}$ incubation, sucB transcripts regained pre-incubation levels (Fig. $4 \mathrm{E}$ ), while icd and fum transcripts were slightly induced (Fig. $4 \mathrm{C}$ and $\mathrm{H}$ ). However, levels of all of these transcripts were depressed after further incubation (2 h) (Fig. 4). In this study, transcription of most TCA cycle genes was induced when glucose was present with acetate for $0.5-1.5 \mathrm{~h}$, but was completely repressed after further incubation with coutilization of glucose and acetate. This analysis demonstrates that glucose represses most genes of TCA cycle metabolism in C. glutamicum.

\section{Analysis of GIxR binding to the promoter region of TCA cycle genes}

To identify GlxR's involvement in controlling the expression of TCA cycle genes, we assessed the ability of purified GlxR to bind to DNA fragments carrying the promoter region of the TCA cycle genes by EMSA. We searched the nucleotide sequence of C. glutamicum for DNA elements with high levels of identity to the GlxR-binding motifs in the promoter/operator regions of TCA cycle genes. A computational search (Vector NTI, Invitrogen) allowing the highest match (up to 3 mismatches out of 10) for each gene with the consensus Crp-binding site (CBS; 5'TGTGA-N ${ }_{6}$-ACACT- $3^{\prime}$ ) revealed 13 sites in or around the promoter regions of TCA cycle genes (Fig. 5A and C). Out of the 13 sites, 6 exhibited high similarity (up to two mismatches) with the CBS consensus motif in the upstream regions of $g l t A, a c n, s u c C D, s d h C A B$, aceA and aceB (Fig. 5A), with sucC having the highest homology with the consensus motif (no mismatch). The nucleotides of the GlxR-binding motifs in the aceB promoter region have 

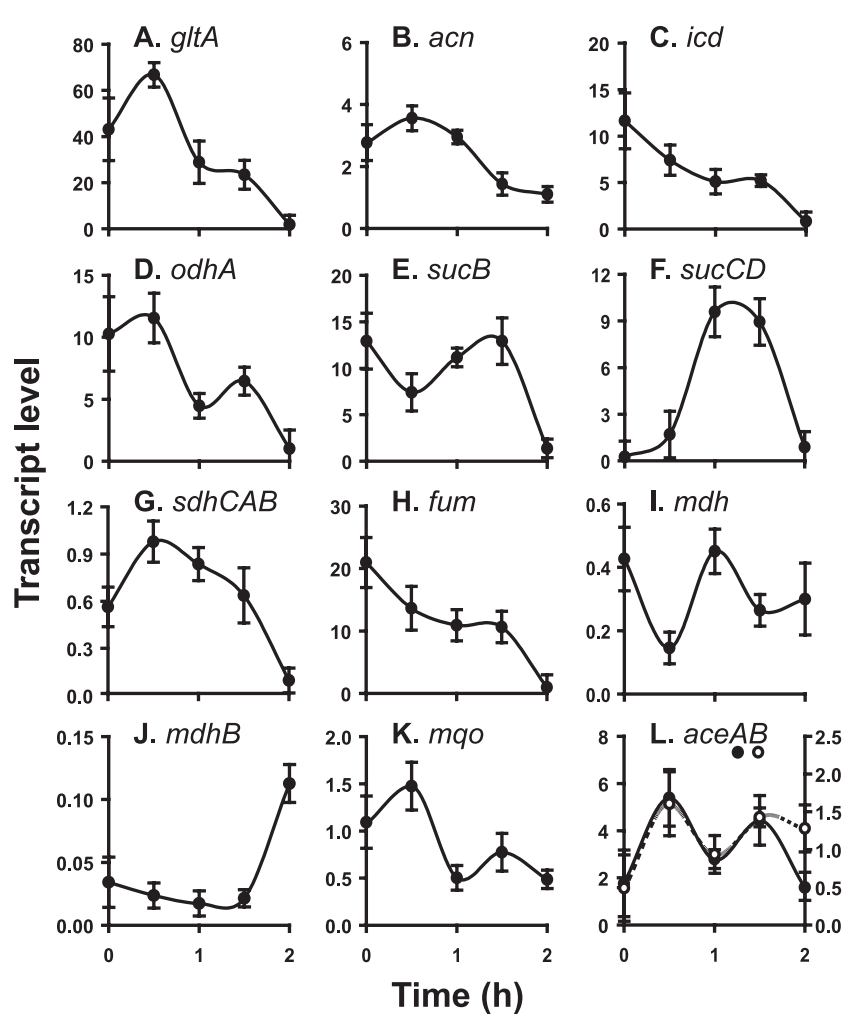

Fig. 4. Time-course of transcription during growth of C. glutamicum on acetate medium with subsequent glucose supplementation, as determined by qRT-PCR. Total RNA (50 $\mathrm{ng}$ ) was isolated from cells grown on $200 \mathrm{mM}$ acetate medium supplemented $(0 \mathrm{~h})$ with $200 \mathrm{mM}$ glucose. The primers, methods and other details correspond to those described in Fig. 1. In panel L, the left scale refers to ace $A$ and the right scale to $a c e B$.

been described previously (Kim et al., 2004; Letek et al., 2006), with two mismatches (Fig. 5A).

His-tagged GlxR protein was purified from E. coli and analysed by SDS-PAGE (Fig. 5B); its molecular mass coincides with the expected size $(25 \mathrm{kDa})$ deduced from the gene sequence. Treating His-tagged GlxR with EnterokinaseMax (Invitrogen) to remove the His tag had no effect on binding (data not shown). In agreement with previous reports (Kim et al., 2004; Letek et al., 2006), the presence of retarded bands was directly dependent on the presence of cAMP in the reaction mixture. No retarded bands were observed in the absence of cAMP or His-tagged GlxR (data not shown). Different amounts of purified GlxR protein (50-500 ng) and DNA fragments (10-100 ng) were used to optimize the binding reaction (data not shown).

As indicated in the previous sections, expression of sucCD was subject to tight carbon regulation. Hence, we first tested whether GlxR recognizes and binds to the promoter region of the sucCD operon by performing mobility shift assays with a $200 \mathrm{bp}$ DNA fragment containing the sucC promoter region (Fig. 5D). When cAMP was added to the binding mixture, a clear band shift was observed for sucC as it was with the positive control aceB (Fig. 5D). In addition, DNA fragments containing the sequences upstream of $g l t A, a c n, s d h C A B$, aceA and aceB (Fig. 5C) appear to bind with GlxR (Fig. 5D). When the DNA fragment of the sequence upstream of fum was used, clear retardation was observed (Fig. 5D), although all possible binding sites upstream of fum exhibited relatively low similarity (three mismatches) with the consensus motif.

\section{Induction of TCA cycle genes in response to various carbon sources}

To further our understanding of gene expression regulation by various carbon sources, we measured the amount of TCA cycle gene transcripts in C. glutamicum cells grown in medium containing different carbon substrates as the sole carbon and energy source. Cells were subcultured in the medium containing the same carbon source before they were added to fresh medium as inocula $\left(\mathrm{OD}_{610}\right.$ 1.8-2.0). After $1 \mathrm{~h}$ incubation, cell growth in the medium was similar with the various carbon sources tested (Fig. 6xiv), although glucose culture showed the highest cell growth. The levels of the TCA cycle gene transcripts varied considerably depending on the nature of the carbon source (Fig. 6i-xiii). Some carbon sources clearly induced stronger expression of certain sets of genes. Acetate caused the expression of all the TCA cycle genes, including $g l t A$, acn, fum, $m d h$, mqo, ace $A$ and $a c e B$, most strongly. In the presence of other nonfermentable carbon sources such as pyruvate or lactate, most TCA cycle genes ( $a c n, i c d, o d h A, s u c B$, fum, $m d h, m d h B$, $m q o$, ace $A$ and $a c e B$ ) were induced to their highest levels (Fig. 6). With non-fermentable carbon along with acetate, the expression of ace $A$ and $a c e B$ was particularly high (Fig. 6xii and xiii). Significant expression of some TCA cycle genes was observed with glucose, but $a c n, \operatorname{suc} C D, \operatorname{sdh} C A B$, ace $A$ and $a c e B$ had the lowest expression levels (Fig. 6vi, vii, xii and xiii). TCA intermediates, such as citrate and succinate, stimulated the expression of most of the genes, including gltA, acn, icd, odhA, sucB, sucCD, sdhCAB, fum, $m d h, m d h B$ and $m q o$, although less effectively (Fig. 6). The sucCD operon of C. glutamicum showed a markedly different pattern of expression from that of other TCA cycle genes. On succinate-containing medium, mRNA levels of sucCD remained at least twofold higher than on acetate, glucose, pyruvate and lactate medium (Fig. 6vi-vii). Similar to $s u c C D$, succinate induction of $s d h C A B$ was observed, and citrate allowed the most significant expression of the $s d h C A B$ gene (Fig. 6vii). Low expression levels of most TCA cycle genes were detected on medium containing malate (Fig. 6).

\section{DISCUSSION}

The TCA cycle is the major catabolic pathway of $C$. glutamicum for generation of carbon backbones and energy. The main objective of this study was to examine 


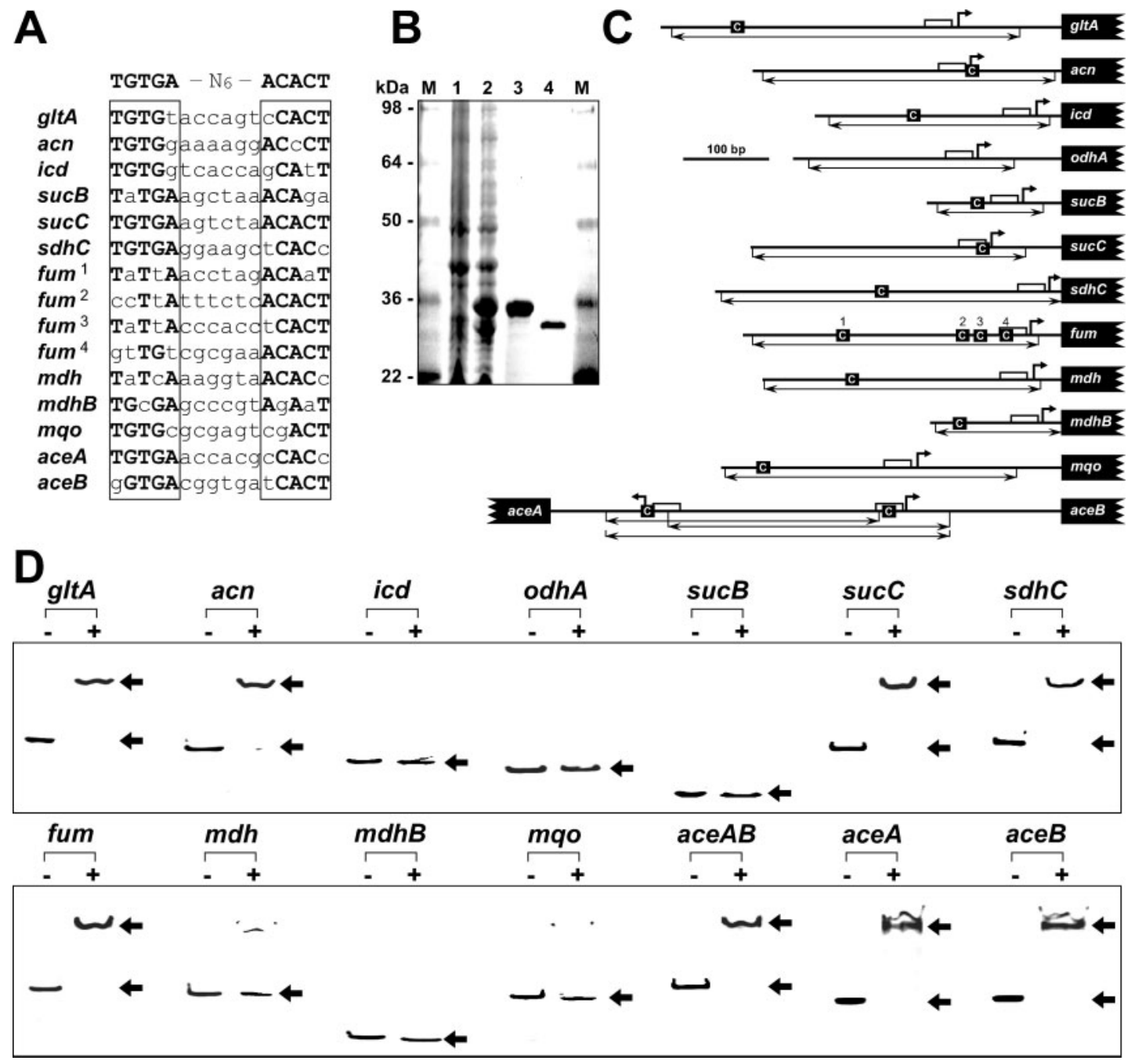

Fig. 5. EMSA with GlxR and TCA cycle genes. (A) Hypothetical presence of CBS consensus motifs in the promoter region. The bold capitalized letters indicate nucleotides conserved with the consensus sequence for catabolite repression shown above. (B) SDS-PAGE of GlxR. Cell extracts of uninduced E. coli (lane 1) and induced E. coli (lane 2); elution fractions containing His-tagged GlxR protein (lane 3); elution fraction containing GlxR without His-tag (lane 4). Molecular mass markers (M) are indicated. (C) Schematic representation of the promoter region. The locations of CBS (C) consensus motifs are indicated by the black boxes. The transcription start points and the promoters $(-10$ and -35$)$ had been determined previously (Han et al., 2008) and are indicated by the bent arrows and white boxes, respectively. Locations of the DNA fragments used in EMSA obtained by PCR amplification using specific primers are indicated by double headed arrows. (D) EMSA of purified GlxR protein (about $200 \mathrm{ng}$ ) incubated with DNA fragments (about $20 \mathrm{ng}$ ) containing the promoter region in the binding buffer including $0.2 \mathrm{mM}$ cAMP; the mixtures were analysed by $5 \%$ PAGE. Lanes labelled '-' contain only the DNA fragment in the reaction mixture; lanes labelled '+' contain purified GlxR protein with DNA fragments. Arrows indicate shifted bands.

in detail the transcriptional regulation of the TCA cycle in C. glutamicum. To investigate the general and specific regulatory patterns in the expression of TCA cycle genes, mRNA was isolated from acetate- or glucose-grown cells taken at various time points. These studies revealed that the TCA cycle genes were coordinately and specifically regulated by acetate and/or glucose in the growth medium, and that this regulation was due to transcriptional control of the respective genes. For instance, acetate induced the transcription of most TCA cycle genes and the time-course of gene transcription was approximately the same in all cases. These data clearly show that all genes involved in corynebacterial TCA cycle are coordinately expressed at the transcriptional level in different growth phases by various substrates such as acetate, glucose, pyruvate and lactose. In general, the expression profiles obtained from C. glutamicum grown in acetate and glucose agree with the direction of intracellular carbon flux. In acetate cultures, genes involved in the TCA cycle ( $g l t A, a c n, s u c C D, s d h C A B$ and fum) and the glyoxylate bypass (aceA and aceB) were highly 


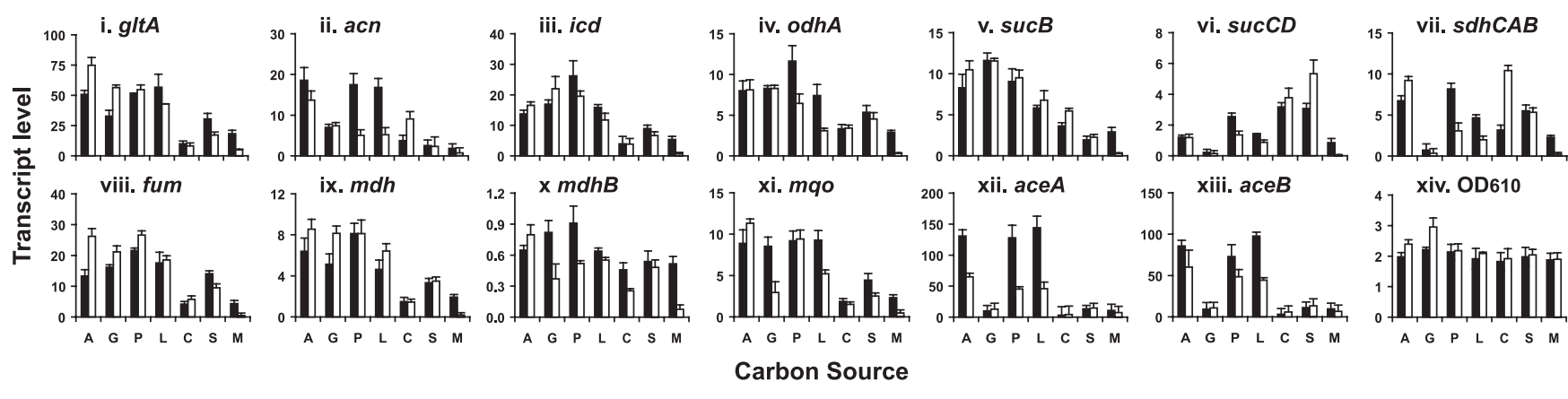

Fig. 6. Levels of induction of C. glutamicum TCA cycle genes by different carbon sources. Total RNA (25 ng) was isolated from C. glutamicum grown on mineral salts medium for $30 \mathrm{~min}$ (black bars) and $60 \mathrm{~min}$ (white bars) after addition of various sole carbon and energy sources: $200 \mathrm{mM}$ of $A$, acetate; $\mathrm{G}$, glucose; $\mathrm{P}$, pyruvate; L, lactate; $\mathrm{C}$, citrate; S, succinate or M, malate. The $\mathrm{OD}_{610}$ is also shown (xiv). The primers, methods and other details correspond to those described in Fig. 1.

upregulated compared with the situation in glucose cultures. The upregulation of these genes is reasonable because these gene products play an important role in acetate metabolism (Przybyla-Zawislak et al., 1999; Wendisch et al., 2000). Similar upregulation of TCA cycle genes in acetate has been reported in B. subtilis (Nakano et al., 1998). In contrast, TCA cycle genes are repressed at high glucose concentrations in the presence of acetate. The transcriptional analysis provided an overall view of the expression of almost all TCA cycle genes and was in good agreement with previous reports of enzyme activities, metabolic arrays and DNA microarrays (Bott, 2007; Kromer et al., 2004; Zhao \& Lin, 2002). The results presented in this work suggest that a common and specific mechanism may exist at the transcriptional level for regulation of TCA cycle genes by different carbon sources, and that this pathway is coordinately regulated to balance the need for energy production and the generation of precursors for anabolism.

TCA cycle genes are regulated by several of the following regulators: Crp, the catabolite repressor activated by cAMP (Saier \& Ramseier, 1996; Zhao \& Lin, 2002); Fnr, whose modulon encodes proteins that are involved in cellular adaptation to growth in anoxic environments (Lynch \& Lin, 1996; Unden \& Schirawski, 1997; Unden et al., 2002); and $\operatorname{ArcA} / \mathrm{ArcB}$, a signal transduction system that regulates gene expression in response to redox conditions (Liu \& De Wulf, 2004; Lynch \& Lin, 1996; Perrenoud \& Sauer, 2005). However, expression of genes encoding enzymes of the TCA cycle and glyoxylate bypass in C. glutamicum has been shown previously to be subject to at least the following five transcriptional regulators: AcnR, a TetR-type repressor of the acn gene (Krug et al., 2005); RipA, a repressor of the acn gene under iron limitation (Wennerhold et al., 2005); RamB, a negative regulator of glyoxylate bypass genes (aceA and aceB) involved in acetate metabolism (Cramer et al., 2006; Gerstmeir et al., 2004); DtxR, a transcriptional regulator of the $s d h C A B$ gene in iron metabolism (Brune et al., 2006); and GlxR, the repressor of the glyoxylate bypass genes (Kim et al., 2004). It is possible that multiple regulators control TCA cycle genes to manifest a complex response to the environment. The glyoxylate bypass genes are transcriptionally regulated by a dual mechanism with GlxR and RamB (Gerstmeir et al., 2004; Kim et al., 2004). Krug et al. (2005) reported that the increased aconitase activity of cells grown on acetate is partially because of decreased repression by $A c n R$ and that an additional transcriptional regulator (besides AcnR) or another regulatory mechanism for aconitase might exist. The only regulatory system that has ubiquitous effects on many different genes is catabolite derepression by cAMP receptor protein (Eraso \& Gancedo, 1984; Kolb et al., 1993; Saier et al., 1996). This regulator activates many genes in the presence of acetate.

One of the features of transcriptional analysis is its utility in predicting gene functions. Although the first three enzymes (GltA, Acn and Icd) at the entry of the TCA cycle are needed for oxoglutarate generation, the regulation of the first two enzymes (GltA and Acn) is somewhat different from that of Icd (Krug et al., 2005; Nakano et al., 1998). In contrast to the mRNA levels of the icd gene, the level of gltA transcripts on acetate-containing medium remained about 1.2-fold higher than on glucose medium, whereas the mRNA level of acn was at least twofold higher on acetate medium than on glucose medium (Fig. 6). These results suggest that $g l t A$ and $a c n$, but not always $i c d$, are closely regulated, which may be due in part to the fact that citrate is an inducer of acn. Furthermore, EMSA showed that proteins such as AcnR (Krug et al., 2005) and GlxR (Fig. 5) bind to the dyad symmetry sequences in the acn promoter region. In addition, both gltA and acn have GlxR operator sites, the target sequence for probable catabolite repression, in their regulatory regions that bind to GlxR. Taken together, these results suggest that gltA and acn regulation might be controlled by the same mechanism. The malate:quinine oxidoreductase gene, mqo, is downregulated by acetate depletion at exponential phase, in contrast to malate dehydrogenase, $m d h$, which is 
upregulated. In addition, the two malate dehydrogenase genes, $m d h$ and $m d h B$, are non-regulated and upregulated, respectively, in acetate depletion at stationary phase. This result suggests that $m d h$ plays a different role from $m d h B$. The expression pattern also suggests that the mqo gene may serve other functions. The inconsistencies between regulation of gene expression and presumed function call for further investigations.

\section{ACKNOWLEDGEMENTS}

This work was financially supported in part by the New Energy and Industrial Technology Development Organization (NEDO, Japan) and a grant (Code\#20080401034002) from the BioGreen 21 Program, Rural Development Administration, Republic of Korea.

\section{REFERENCES}

Arndt, A. \& Eikmanns, B. J. (2007). The alcohol dehydrogenase gene adhA in Corynebacterium glutamicum is subject to carbon catabolite repression. J Bacteriol 189, 7408-7416.

Bott, M. (2007). Offering surprises: TCA cycle regulation in Corynebacterium glutamicum. Trends Microbiol 15, 417-425.

Bruckner, R. \& Titgemeyer, F. (2002). Carbon catabolite repression in bacteria: choice of the carbon source and autoregulatory limitation of sugar utilization. FEMS Microbiol Lett 209, 141-148.

Brune, I., Werner, H., Huser, A., Kalinowski, J., Puhler, A. \& Tauch, A. (2006). The DtxR protein acting as dual transcriptional regulator directs a global regulatory network involved in iron metabolism of Corynebacterium glutamicum. BMC Genomics 7, 21.

Bustin, S. A. (2002). Quantification of mRNA using real-time reverse transcription PCR (RT-PCR): trends and problems. J Mol Endocrinol 29, 23-39.

Cox, D. P. \& Hanson, R. S. (1968). Catabolite repression of aconitate hydratase in Bacillus subtilis. Biochim Biophys Acta 158, 36-44.

Cramer, A., Gerstmeir, R., Schaffer, S., Bott, M. \& Eikmanns, B. J. (2006). Identification of RamA, a novel LuxR-type transcriptional regulator of genes involved in acetate metabolism of Corynebacterium glutamicum. J Bacteriol 188, 2554-2567.

Cunningham, L., Gruer, M. J. \& Guest, J. R. (1997). Transcriptional regulation of the aconitase genes (acnA and $a c n B$ ) of Escherichia coli. Microbiology 143, 3795-3805.

Dover, L. G., Cerdeno-Tarraga, A. M., Pallen, M. J., Parkhill, J. \& Besra, G. S. (2004). Comparative cell wall core biosynthesis in the mycolated pathogens, Mycobacterium tuberculosis and Corynebacterium diphtheriae. FEMS Microbiol Rev 28, 225-250.

Eikmanns, B. J., Thum-Schmitz, N., Eggeling, L., Ludtke, K. U. \& Sahm, H. (1994). Nucleotide sequence, expression and transcriptional analysis of the Corynebacterium glutamicum gltA gene encoding citrate synthase. Microbiology 140, 1817-1828.

Eikmanns, B. J., Rittmann, D. \& Sahm, H. (1995). Cloning, sequence analysis, expression, and inactivation of the Corynebacterium glutamicum icd gene encoding isocitrate dehydrogenase and biochemical characterization of the enzyme. J Bacteriol 177, 774-782.

Eraso, P. \& Gancedo, J. M. (1984). Catabolite repression in yeasts is not associated with low levels of cAMP. Eur J Biochem 141, 195-198.

Fouet, A. \& Sonenshein, A. L. (1990). A target for carbon sourcedependent negative regulation of the citB promoter of Bacillus subtilis. J Bacteriol 172, 835-844.
Fouet, A., Jin, S. F., Raffel, G. \& Sonenshein, A. L. (1990). Multiple regulatory sites in the Bacillus subtilis citB promoter region. J Bacteriol 172, 5408-5415.

Funke, G., von Graevenitz, A., Clarridge, J. E., III \& Bernard, K. A. (1997). Clinical microbiology of coryneform bacteria. Clin Microbiol Rev 10, 125-159.

Genda, T., Nakamatsu, T. \& Ozak, H. (2003). Purification and characterization of malate dehydrogenase from Corynebacterium glutamicum. J Biosci Bioeng 95, 562-566.

Genda, T., Watabe, S. \& Ozaki, H. (2006). Purification and characterization of fumarase from Corynebacterium glutamicum. Biosci Biotechnol Biochem 70, 1102-1109.

Gerstmeir, R., Wendisch, V. F., Schnicke, S., Ruan, H., Farwick, M., Reinscheid, D. \& Eikmanns, B. J. (2003). Acetate metabolism and its regulation in Corynebacterium glutamicum. J Biotechnol 104, 99-122.

Gerstmeir, R., Cramer, A., Dangel, P., Schaffer, S. \& Eikmanns, B. J. (2004). RamB, a novel transcriptional regulator of genes involved in acetate metabolism of Corynebacterium glutamicum. J Bacteriol 186, 2798-2809.

Gruer, M. J. \& Guest, J. R. (1994). Two genetically-distinct and differentially-regulated aconitases (AcnA and AcnB) in Escherichia coli. Microbiology 140, 2531-2541.

Gruer, M. J., Bradbury, A. J. \& Guest, J. R. (1997). Construction and properties of aconitase mutants of Escherichia coli. Microbiology 143, 1837-1846.

Han, S. O., Inui, M. \& Yukawa, H. (2007). Expression of Corynebacterium glutamicum glycolytic genes varies with carbon source and growth phase. Microbiology 153, 2190-2202.

Han, S. O., Inui, M. \& Yukawa, H. (2008). Transcription of Corynebacterium glutamicum genes involved in tricarboxylic acid cycle and glyoxylate cycle. J Mol Microbiol Biotechnol, Feb 20 [Epub ahead of print]

Hanson, R. S. \& Cox, D. P. (1967). Effect of different nutritional conditions on the synthesis of tricarboxylic acid cycle enzymes. J Bacteriol 93, 1777-1787.

Hayashi, M., Mizoguchi, H., Shiraishi, N., Obayashi, M., Nakagawa, S., Imai, J., Watanabe, S., Ota, T. \& Ikeda, M. (2002). Transcriptome analysis of acetate metabolism in Corynebacterium glutamicum using a newly developed metabolic array. Biosci Biotechnol Biochem 66, 1337-1344.

Jin, S. \& Sonenshein, A. L. (1994). Transcriptional regulation of Bacillus subtilis citrate synthase genes. J Bacteriol 176, 4680-4690.

Kalinowski, J., Bathe, B., Bartels, D., Bischoff, N., Bott, M., Burkovski, A., Dusch, N., Eggeling, L., Eikmanns, B. J. \& other authors (2003). The complete Corynebacterium glutamicum ATCC 13032 genome sequence and its impact on the production of Laspartate-derived amino acids and vitamins. J Biotechnol 104, 5-25.

Kim, H. J., Kim, T. H., Kim, Y. \& Lee, H. S. (2004). Identification and characterization of $g l x R$, a gene involved in regulation of glyoxylate bypass in Corynebacterium glutamicum. J Bacteriol 186, 3453-3460.

Kinoshita, S. \& Tanaka, K. (1972). Glutamic acid. In The Microbial Production of Amino Acids, pp. 263-324. Edited by K. Yamada. New York: John Wiley.

Kinoshita, S., Udaka, S. \& Shimono, M. (1957). Studies on the amino acid fermentation Part I. Production of L-glutamic acid by various microorganisms. J Gen Microbiol 3, 193-205.

Kolb, A., Busby, S., Buc, H., Garges, S. \& Adhya, S. (1993). Transcriptional regulation by cAMP and its receptor protein. Annu Rev Biochem 62, 749-795.

Kotrbova-Kozak, A., Kotrba, P., Inui, M., Sajdok, J. \& Yukawa, H. (2007). Transcriptionally regulated adhA gene encodes alcohol 
dehydrogenase required for ethanol and n-propanol utilization in Corynebacterium glutamicum R. Appl Microbiol Biotechnol 76, 1347-1356.

Kramer, R., Lambert, C., Hoischen, C. \& Ebbighausen, H. (1990). Uptake of glutamate in Corynebacterium glutamicum. 1. Kinetic properties and regulation by internal $\mathrm{pH}$ and potassium. Eur $\mathrm{J}$ Biochem 194, 929-935.

Kromer, J. O., Sorgenfrei, O., Klopprogge, K., Heinzle, E. \& Wittmann, C. (2004). In-depth profiling of lysine-producing Corynebacterium glutamicum by combined analysis of the transcriptome, metabolome, and fluxome. J Bacteriol 186, 1769-1784.

Kronemeyer, W., Peekhaus, N., Kramer, R., Sahm, H. \& Eggeling, L. (1995). Structure of the gluABCD cluster encoding the glutamate uptake system of Corynebacterium glutamicum. J Bacteriol 177, 1152-1158.

Krug, A., Wendisch, V. F. \& Bott, M. (2005). Identification of AcnR, a TetR-type repressor of the aconitase gene acn in Corynebacterium glutamicum. J Biol Chem 280, 585-595.

Laemmli, U. K. (1970). Cleavage of structural proteins during the assembly of the head of bacteriophage T4. Nature 227, 680-685.

Letek, M., Valbuena, N., Ramos, A., Ordonez, E., Gil, J. A. \& Mateos, L. M. (2006). Characterization and use of catabolite-repressed promoters from gluconate genes in Corynebacterium glutamicum. J Bacteriol 188, 409-423.

Liebl, W. (1991). The genus Corynebacterium - nonmedical. In The Prokaryotes, pp. 1157-1171. Edited by A. Balows, H. G. Trüper, M. Dworkin, W. Harder \& K. H. Schleifer. New York: Springer-Verlag.

Liebl, W. (2005). Corynebacterium taxonomy. In Handbook on Corynebacterium glutamicum, pp. 9-34. Edited by L. Eggeling \& M. Bott. Boca Raton, FL: CRC Press.

Liu, X. \& De Wulf, P. (2004). Probing the ArcA-P modulon of Escherichia coli by whole genome transcriptional analysis and sequence recognition profiling. J Biol Chem 279, 12588-12597.

Lynch, A. S. \& Lin, E. C. C. (1996). Responses to molecular oxygen. In Escherichia coli and Salmonella: Cellular and Molecular Biology, 2nd edn, pp. 1526-1538. Edited by F. C. Neidhardt and others. Washington, DC: American Society for Microbiology.

Molenaar, D., van der Rest, M. E. \& Petrovic, S. (1998). Biochemical and genetic characterization of the membrane-associated malate dehydrogenase (acceptor) from Corynebacterium glutamicum. Eur J Biochem 254, 395-403.

Molenaar, D., van der Rest, M. E., Drysch, A. \& Yucel, R. (2000). Functions of the membrane-associated and cytoplasmic malate dehydrogenases in the citric acid cycle of Corynebacterium glutamicum. J Bacteriol 182, 6884-6891.

Muffler, A., Bettermann, S., Haushalter, M., Horlein, A., Neveling, U., Schramm, M. \& Sorgenfrei, O. (2002). Genome-wide transcription profiling of Corynebacterium glutamicum after heat shock and during growth on acetate and glucose. J Biotechnol 98, 255-268.

Nakano, M. M., Zuber, P. \& Sonenshein, A. L. (1998). Anaerobic regulation of Bacillus subtilis Krebs cycle genes. J Bacteriol 180, 3304-3311.

Nishimura, T., Vertès, A., Shinoda, Y., Inui, M. \& Yukawa, H. (2007). Anaerobic growth of Corynebacterium glutamicum using nitrate as a terminal electron acceptor. Appl Microbiol Biotechnol 75, 889-897.

Ohne, M. (1974). Regulation of aconitase synthesis in Bacillus subtilis: induction, feedback repression, and catabolite repression. J Bacteriol 117, 1295-1305.
Perrenoud, A. \& Sauer, U. (2005). Impact of global transcriptional regulation by $\mathrm{ArcA}, \mathrm{ArcB}, \mathrm{Cra}, \mathrm{Crp}$, Cya, Fnr, and Mlc on glucose catabolism in Escherichia coli. J Bacteriol 187, 3171-3179.

Przybyla-Zawislak, B., Gadde, D. M., Ducharme, K. \& McCammon, M. T. (1999). Genetic and biochemical interactions involving tricarboxylic acid cycle (TCA) function using a collection of mutants defective in all TCA cycle genes. Genetics 152, 153-166.

Reinscheid, D. J., Eikmanns, B. J. \& Sahm, H. (1994a). Malate synthase from Corynebacterium glutamicum: sequence analysis of the gene and biochemical characterization of the enzyme. Microbiology 140, 3099-3108.

Reinscheid, D. J., Eikmanns, B. J. \& Sahm, H. (1994b). Characterization of the isocitrate lyase gene from Corynebacterium glutamicum and biochemical analysis of the enzyme. J Bacteriol 176, 3474-3483.

Rosenkrantz, M. S., Dingman, D. W. \& Sonenshein, A. L. (1985). Bacillus subtilis citB gene is regulated synergistically by glucose and glutamine. J Bacteriol 164, 155-164.

Saier, M. H., Jr \& Ramseier, T. M. (1996). The catabolite repressor/ activator (Cra) protein of enteric bacteria. J Bacteriol 178, 3411-3417.

Saier, M. H., Jr, Chauvaux, S., Cook, G. M., Deutscher, J., Paulsen, I. T., Reizer, J. \& Ye, J. J. (1996). Catabolite repression and inducer control in Gram-positive bacteria. Microbiology 142, 217-230.

Unden, G. \& Schirawski, J. (1997). The oxygen-responsive transcriptional regulator FNR of Escherichia coli: the search for signals and reactions. Mol Microbiol 25, 205-210.

Unden, G., Achebach, S., Holighaus, G., Tran, H. G., Wackwitz, B. \& Zeuner, Y. (2002). Control of FNR function of Escherichia coli by $\mathrm{O}_{2}$ and reducing conditions. J Mol Microbiol Biotechnol 4, 263-268.

Usuda, Y., Tujimoto, N., Abe, C., Asakura, Y., Kimura, E., Kawahara, Y., Kurahashi, O. \& Matsui, H. (1996). Molecular cloning of the Corynebacterium glutamicum (Brevibacterium lactofermentum AJ12036) odhA gene encoding a novel type of 2-oxoglutarate dehydrogenase. Microbiology 142, 3347-3354.

Wendisch, V. F., de Graaf, A. A., Sahm, H. \& Eikmanns, B. J. (2000). Quantitative determination of metabolic fluxes during coutilization of two carbon sources: comparative analyses with Corynebacterium glutamicum during growth on acetate and/or glucose. J Bacteriol 182, 3088-3096.

Wennerhold, J., Krug, A. \& Bott, M. (2005). The AraC-type regulator RipA represses aconitase and other iron proteins from Corynebacterium under iron limitation and is itself repressed by DtxR. J Biol Chem 280, 40500-40508.

Winer, J., Jung, C. K. S., Shackel, I. \& Williams, P. M. (1999). Development and validation of real-time quantitative reverse transcriptase-polymerase chain reaction for monitoring gene expression in cardiac myocytes in vitro. Anal Biochem 270, 41-49.

Wittmann, C. \& De Graaf, A. A. (2005). Metabolic flux analysis in Corynebacterium glutamicum. In Handbook on Corynebacterium glutamicum, pp. 277-304. Edited by L. Eggeling \& M. Bott. Boca Raton, FL: CRC Press.

Yukawa, H., Omumasaba, C. A., Nonaka, H., Kós, P., Okai, N., Suzuki, N., Suda, M., Tsuge, Y., Watanabe, J. \& other authors (2007). Comparative analysis of the Corynebacterium glutamicum group and complete genome sequence of strain R. Microbiology 153, 1042-1058.

Zhao, Y. \& Lin, Y.-H. (2002). Flux distribution and partitioning in Corynebacterium glutamicum grown at different specific growth rates. Process Biochem 37, 775-785.

Edited by: M. Hecker 